\title{
AN ANALYSIS OF THE ACTION OF ATP AND RE- LATED COMPOUNDS ON MEMBRANE CURRENT AND TENSION COMPONENTS IN BULLFROG ATRIAL MUSCLE
}

\author{
Masayosi Goto, Atsuko Yatani, and Yasuo Tsuda \\ Department of Physiology, Faculty of Medicine, \\ Kyushu University, Fukuoka 812, Japan
}

\begin{abstract}
The effect of adenosine compounds (ATP, ADP, AMP, and adenosine) on membrane potential, current and contractile tension on the bullfrog atrium were studied under voltage clamped and unclamped conditions. The compounds produced immediate positive and late negative inotropic effects in unclamped conditions. The positive inotropic effect and the potency of drugs appeared less marked in the order of ATP, ADP, AMP, and adenosine. Under voltage clamped conditions, only the energy rich compounds, ATP and ADP, produced an enhancement of calcium inward current $\left(I_{\mathrm{Ca}}\right)$ and $I_{\mathrm{Ca}}$-dependent phasic tension, while AMP and adenosine elicited a negative inotropic effect. The delayed outward current was initially depressed but later augmented especially in case of ATP and ADP where $I_{\mathrm{Ca}}$ was enhanced. All adenosine compounds, however, inhibited the $I_{\mathrm{Ca}}$-independent tonic tension. This effect, appearing nonspecific, was ascribable to the action of common structure of these compounds, purine-riboside moiety.
\end{abstract}

It is generally thought that in the myocardium a close relationship exists between the level of glycolysis and transmembrane electrical activity (MACLEOD and Daniel, 1965; MACLeOd and Prasad, 1969; Prasad and Macleod, 1969), and the duration of the action potential is related to the amount of ATP derived mainly from glycolysis (MCDonald et al., 1971; MCDonald and MACLeOD, 1971, 1973; GirARDier, 1971/72; Cheneval et al., 1972).

The effect of exogenously applied adenosine compounds, however, has not been consistent in the results. Compounds such as ATP, ADP, AMP, and adenosine, except membrane permeable cyclic AMP derivatives, depressed the contractility of rat, rabbit, cat and guinea-pig isolated atria (HollANDER and WeBB, 1957; Bertelli et al., 1972; MeINERTZ et al., 1973) producing a marked

Received for publication October 29, 1976

後藤昌義, 八谷アッ子, 津田泰夫 
shortening of action potential, and inhibited the slow action potential of potassiumdepolarized guinea-pig atrial muscle (ScHRADER et al., 1975). Whereas, in frog ventricle a dramatic recovery of contractile force and prolongation of action potential occurred after addition of ATP in the Ca-deficient condition (ANTONI et al., 1960), and even slow action potential in partially depolarized guinea-pig heart was produced (SCHNEIDER and SPERELAKIS, 1975).

These discrepancies suggest the existence of dual sites of action of ATP, which might be variable depending on the experimental conditions or the use of different species. No analysis with the voltage clamp technique, however, has been done on the mode of action. Therefore, the present experiments were undertaken to analyse the effects of ATP and adenosine compounds on the membrane currents and tension components in the bullfrog atrium in which the currents and excitation-contraction coupling processes have been well clarified (VASSORT and Rougier, 1972; Coraboeuf, 1974).

\section{METHODS}

Muscle bundles isolated from the right atrium of the bullfrog, Rana catesbiana, were used. After the atrium was opened and the interatrial septum was removed, the atrial muscle bundles which run to the atrio-ventricular valves were exposed. A thin strip of bundles which appeared to be parallel was isolated carefully, and the epicardium was removed under a binocular microscope. The length of the strip was 5-7 mm, and the diameter $0.4-0.6 \mathrm{~mm}$.

The membrane potential, current and tension were measured simultaneously using the conventional double-gap method described in a preceding report (Gото et al., 1974). The width of the central test gap was $0.3-0.5 \mathrm{~mm}$ and those of intermediate gaps were $1.0 \mathrm{~mm}$. The two terminal compartments of the bath were initially perfused with normal Ringer solution and subsequently with isotonic $\mathrm{KCl}$ Ringer so that a trans-gap resting potential could be measured. With this apparatus a gap resting potential of $70-80 \mathrm{mV}$ and a gap action potential of 100 $120 \mathrm{mV}$ were commonly obtained. When the membrane potential was clamped, the potential was usually held at the gap resting potential and a rectangular step pulse either of depolarization or hyperpolarization was applied with intervals of more than $10 \mathrm{sec}$.

The compositions of the normal Ringer and test solutions used for the purpose

Table 1. Composition of solutions (mm/liter).

\begin{tabular}{|c|c|c|c|c|c|c|c|c|}
\hline Solution & $\mathrm{NaCl}$ & Sucrose & $\mathrm{KCl}$ & $\begin{array}{l}\mathrm{CaCl}_{2} \\
2 \mathrm{H}_{2} \mathrm{O}\end{array}$ & Tris-Cl & EDTA & $\begin{array}{c}\mathrm{MnCl}_{2} \\
4 \mathrm{H}_{2} \mathrm{O}\end{array}$ & Glucose \\
\hline A) & 109.84 & - & 2.56 & 1.80 & 10.0 & - & - & 5.80 \\
\hline B) & - & 219.67 & 2.56 & 1.80 & 10.0 & - & - & 5.80 \\
\hline C) & 109.84 & - & 2.56 & - & 10.0 & $5 \times 10^{-2}$ & - & 5.80 \\
\hline D) & 109.84 & - & 2.56 & 1.80 & 10.0 & - & 3.00 & 5.80 \\
\hline
\end{tabular}


of isolation of specific membrane currents are shown in Table 1. In this table, solution A is the normal Ringer. Solution B is Na-free sucrose Ringer in which $\mathrm{Ca}$ inward current was isolated. Solution $\mathrm{C}$ is Ca-free, EDTA Ringer, and with freshly added TTX $\left(5 \times 10^{-7} \mathrm{~g} / \mathrm{ml}\right)$ slow Na inward current was isolated. Solution $\mathrm{D}$ is Ringer solution containing $\mathrm{Mn}$. In this solution the slow channel was blocked, and fast $\mathrm{Na}$ inward current and $\mathrm{K}$ outward currents were analysed.

As adenosine compounds, ATP, ADP, and AMP in sodium salt, and adenosine (Boehringer) were used. These compounds were freshly added to the basic perfusing solutions.

All experiments were performed at a temperature $17 \pm 1^{\circ} \mathrm{C}$, which was controlled with a thermoregulator. At this temperature the normal electrical activity of the preparation was maintained longer (for 3-4 hr) than at higher temperatures.

\section{RESULTS}

1. General effects of ATP on the membrane potential and contractile tension

The action of ATP in various concentrations $(0.01,0.02,0.05,0.1,0.2,0.5$,
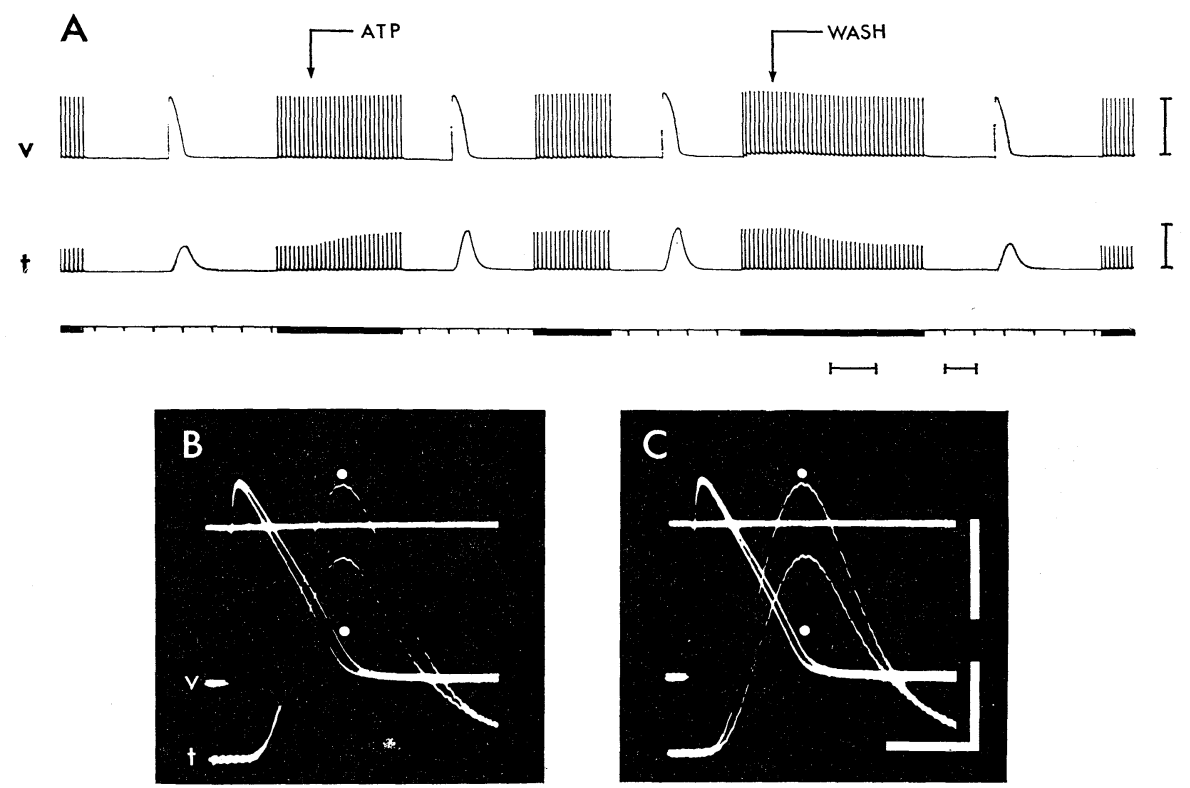

Fig. 1. A) Effects of ATP (0.1 mM) on the membrane potential (v) and the tension (t). Vertical calibrations are $100 \mathrm{mV}$ and $0.05 \mathrm{~g}$. Horizontal calibrations are $1.0 \mathrm{~min}$ and $1.0 \mathrm{sec}$ for the slow and fast records, respectively. B) Superimposed record of the responses before and 3 min after introduction of ATP $(0.1 \mathrm{mM})$. C) The same but the responses $5 \mathrm{~min}$ after the introduction and $7 \mathrm{~min}$ after washing. White dots mark the presence of ATP. The upper vertical calibration is $50 \mathrm{mV}$ and the lower one, $0.01 \mathrm{~g}$. Horizontal calibration marks $0.4 \mathrm{sec}$. 
and $1.0 \mathrm{~mm}$ ) was examined. ATP as low as $0.01 \mathrm{~mm}$ initiated a positive inotropic effect on the bullfrog atrial muscle. The effect increased with concentration of ATP up to $0.2 \mathrm{~mm}$ where almost maximal tension was attained. A part of the effects of ATP $(0.1 \mathrm{~mm})$ is shown in Fig. 1 in which the gap membrane potential and contractile tension were recorded simultaneously. ATP produced an immediate increase of the overshoot and duration of action potential (AP), and a marked augmentation of twitch contraction promoting the rate of rise and fall of tension. The time to peak tension, contraction duration, and basal tension as well as the gap resting potential did not show any appreciable change. The effects of ATP generally attained maximum within 3-5 min after the application and were sustained for several minutes. The reversibility after washing and the reproducibility of the effects were excellent.

Above concentrations of $0.1 \mathrm{~mm}$, however, a negative inotropic phase followed the initial positive phase. Generally, the negative phase, appearing faster in the higher concentrations of ATP, was accompanied by a gradual shortening of $\mathrm{AP}$ and a decrease in the overshoot and amplitude.

It is reported that a positive inotropic effect produced by guanosine and related compounds (6-OH purines) is the results of release of endogeneous noradrenaline (Rosenblum and SteIn, 1964). Although no such effect was observed in case of adenosine and its derivatives (6- $\mathrm{NH}_{2}$ purines), we examined ATP action under constant presence of $\beta$-adrenergic blockers, propranolol $\left(10^{-6} \mathrm{M}\right)$ and pindlol $\left(10^{-7} \mathrm{M}\right)$. No fundamental change, however, was noticed in the effects of ATP.

2. Effects of ATP under voltage clamp

General effects of ATP (0.01-1.0 mM) on the membrane current and contractile tension under voltage clamp were examined with rectangular depolarizing

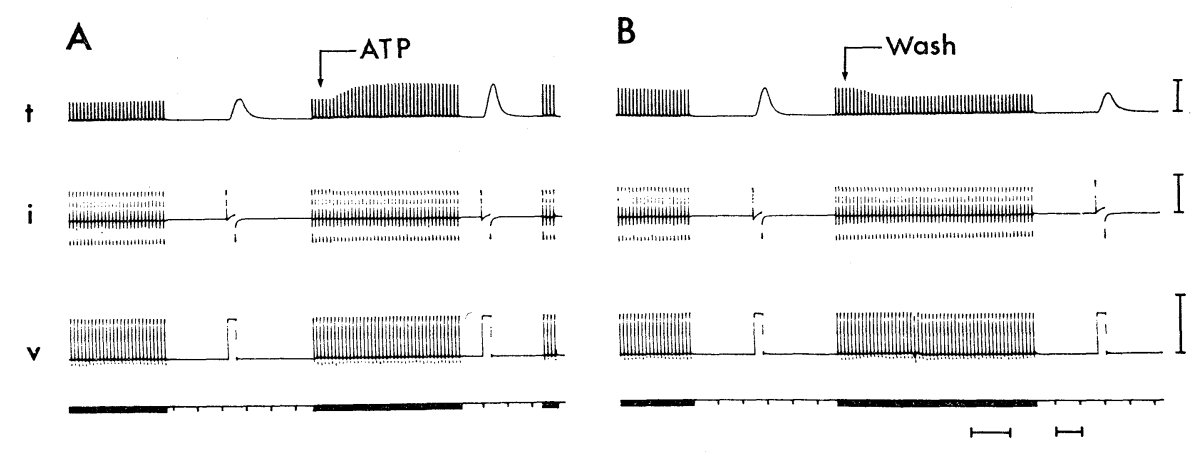

Fig. 2. Effects of ATP ( $0.05 \mathrm{~mm})$ on the tension $(t)$ and the membrane current (i) of the bullfrog atrial muscle under voltage clamp (v). Short depolarizing pulses $(75 \mathrm{mV}$, $0.4 \mathrm{sec}$ ) were applied with $10 \mathrm{sec}$ intervals from the holding potential of $-70 \mathrm{mV}$. A) and $B$ ) are the same series of record with 4 min interception. Vertical bars from the top to the bottom are $0.05 \mathrm{~g}, 10 \mu \mathrm{A}$, and $100 \mathrm{mV}$. Horizontal calibrations are $1.0 \mathrm{~min}$ and $1.0 \mathrm{sec}$ for slow and fast records, respectively. 
pulses. Figure 2 shows one of the typical records on the effects of ATP $(0.05 \mathrm{~mm})$ in which $75 \mathrm{mV}, 0.4 \mathrm{sec}$ depolarizing pulses were applied. ATP again produced a marked augmentation of contractile tension, accompanied by a slight increase in the inward current. The augmented contraction, however, gradually diminished with time after $10 \mathrm{~min}$. These results may indicate that the positive inotropic effect observed in unclamped conditions was not simply due to an increase of AP amplitude and/or duration but also to a definite augmentation of the excitationcontraction coupling, presumably by increasing $I_{\mathrm{Ca}}$.

Figure $3 \mathrm{~A}$ shows the effects of ATP $(0.05 \mathrm{~mm})$ on the time-course of the membrane current and tension in response to $50 \mathrm{mV}$ depolarization, in which the responses before and $3 \mathrm{~min}$ after the application of ATP were photographically

A

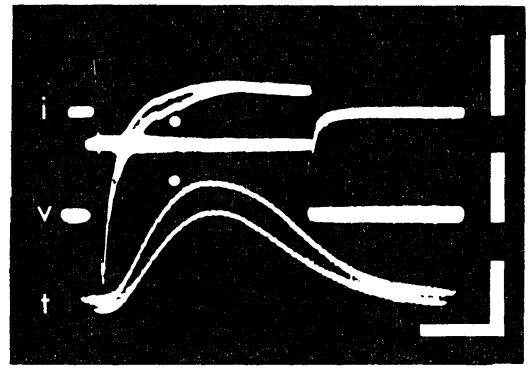

B
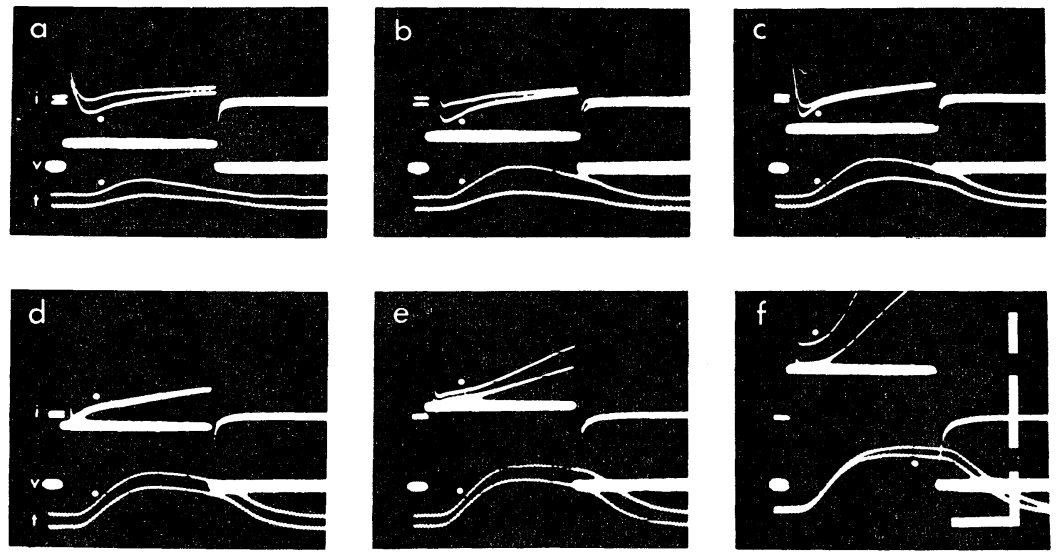

Fig. 3. Effects of ATP (0.05 mM) on the membrane current (i) and the tension ( $t$ ) in response to depolarizing pulses (v). The depolarizing pulses lasting $1.0 \mathrm{sec}$ were applied from a holding potential of $-75 \mathrm{mV}$. A) The effects in normal Ringer solution. The responses to $50 \mathrm{mV}$ depolarization before and $3 \mathrm{~min}$ after ATP (white dots) were artificially superimposed. Vertical calibrations from the top to the bottom are $10 \mu \mathrm{A}, 50 \mathrm{mV}$ and $0.02 \mathrm{~g}$. B) The effects in TTX $\left(5 \times 10^{-7} \mathrm{~g} / \mathrm{ml}\right)$ containing Ringer solution. The responses to the same depolarization in different amplitude before and 8-10 min after ATP (white dots) were similarly superimposed. Vertical calibrations from the top to the bottom are $5 \mu \mathrm{A}, 100 \mathrm{mV}$, and $0.1 \mathrm{~g}$. In both $\mathrm{A}$ and $\mathrm{B}$, horizontal bars mark $0.4 \mathrm{sec}$. 
superimposed. As indicated by dots, a marked augmentation of contraction was produced accompanied by an increase in the tail part of the inward current, while the peak amplitude of the fast spike $\left(I_{\mathrm{Naf}}\right)$ was not affected. These data may suggest that ATP enhances contractile tension by increasing the slow inward current.

Therefore, under constant presence of TTX $\left(5 \times 10^{-7} \mathrm{~g} / \mathrm{ml}\right)$ the effect of ATP was further examined. Figure $3 \mathrm{~B}$ shows a part of the data where depolarizing pulses of different amplitude and $1 \mathrm{sec}$ duration were applied and the records of responses to the same depolarizing pulse before and after introduction of ATP $(0.05 \mathrm{~mm})$ were artificially superimposed. As can be seen in the upper panels (Fig. 3a, b, c), the slow inward current and the contractile tension were considerably augmented at the low voltage range of depolarization, while at the higher voltages (Fig. 3d, e, f) the tension was unchanged or rather suppressed. The outward current appeared markedly augmented for the pulses stronger than $100 \mathrm{mV}$ (Fig. 3e, f), but the slight shift in the basal current level was uncommon.

Figure $4 \mathrm{~A}$ illustrates the effects of ATP $(0.05 \mathrm{~mm})$ on the voltage-current relationships under constant presence of TTX $\left(5 \times 10^{-7} \mathrm{~g} / \mathrm{ml}\right)$. A marked increase of the slow inward current and an augmentation of the outward current were apparent for the relatively low (less than $80 \mathrm{mV}$ ) and high depolarizations (more than $60 \mathrm{mV}$ ), respectively. The peak of the inward current shifted left-
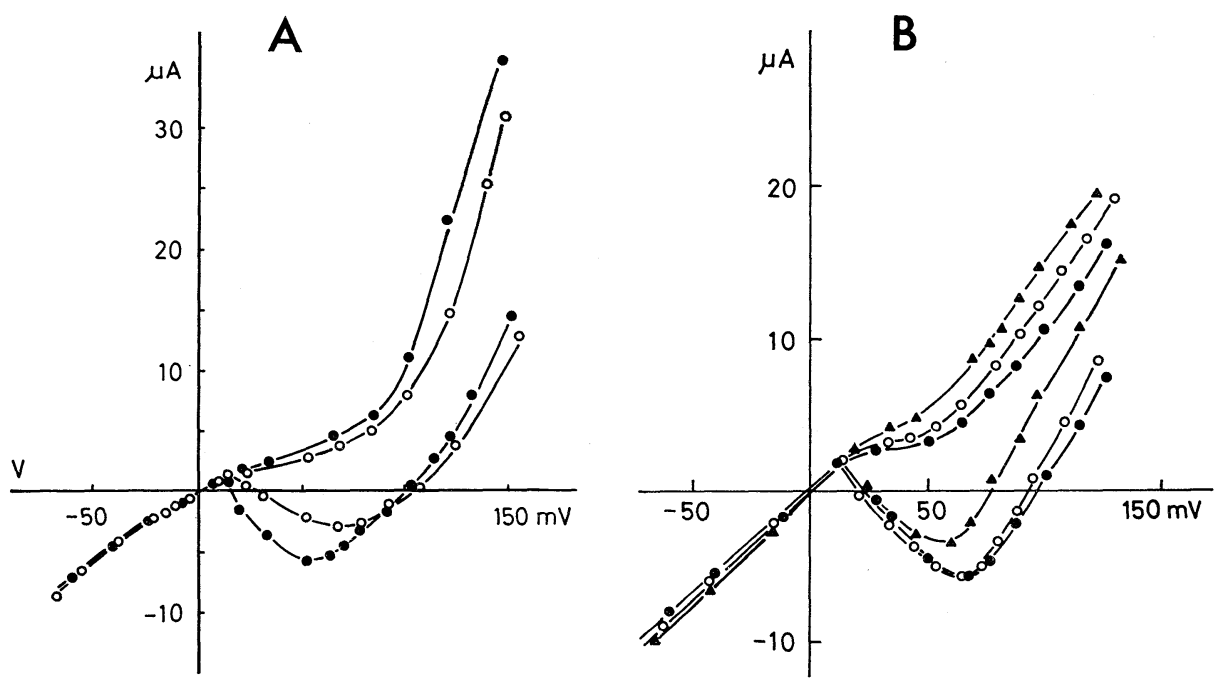

Fig. 4. A comparison of the effects of ATP and AMP. A) Voltage-current relationships before $(O)$ and 10-12 min after application $(\bullet)$ of ATP $(0.05 \mathrm{~mm})$ in the presence of TTX $\left(5 \times 10^{-7} \mathrm{~g} / \mathrm{ml}\right)$. Note an augmentation of the slow inward current. The delayed outward current was also enhanced at this phase. B) Voltage-current relationships in the control (O), 5-7 $\mathrm{min}(\bullet)$ and 18-20 $\mathrm{min}(\mathbf{\Delta})$ after application of AMP (1.0 mM). In both of A and B test pulse duration was $1.0 \mathrm{sec}$ and TTX was present throughout. 
wards about $15 \mathrm{mV}$. Terminal current levels at the ends of hyperpolarizing and depolarizing pulses of less than $\pm 60 \mathrm{mV}$ did not change after ATP. These facts may indicate that neither the leaky current nor the membrane resistance was affected by ATP, and that the anomalous rectification of the membrane also remained unchanged in this voltage range. Meanwhile, a marked increase in the outward current for strong depolarizing pulses was presumed mainly due to an increase of $I_{x}$, because the activation voltage of the current was known to be $-55-+50 \mathrm{mV}$ (Brown and Noble, 1969).

\section{Effects of ATP on the current components}

Figure 5 illustrates the effects of ATP $(0.1 \mathrm{~mm})$ on the voltage-current relationships in the modified Ringer solutions (Table 1). In the Na-free sucrose

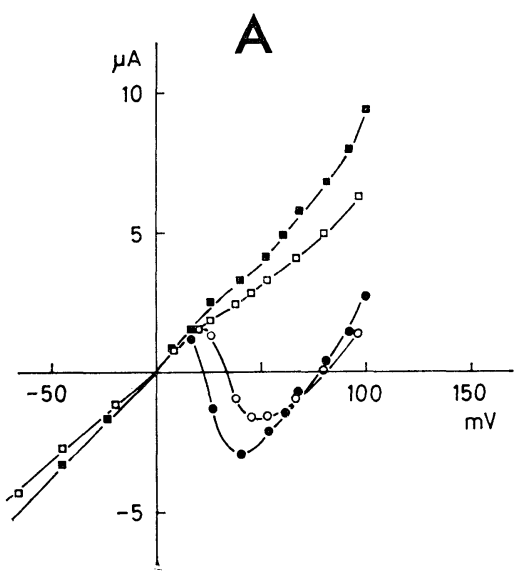

Na-free

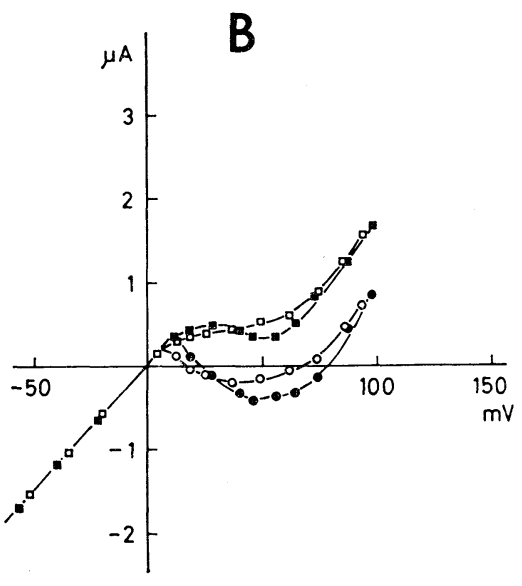

Ca-free+EDTA

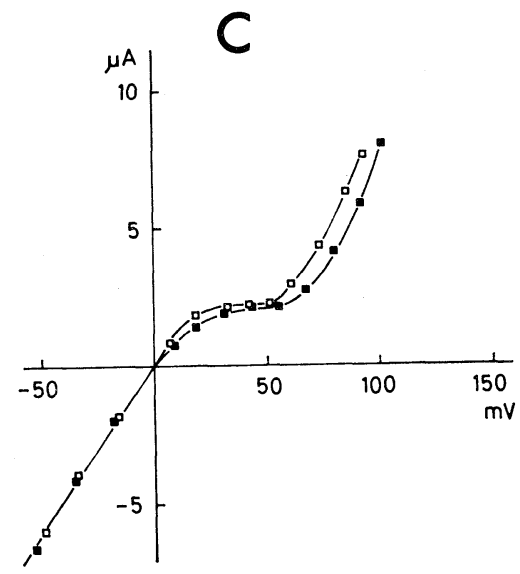

Mn $3 \mathrm{~mm}$
Fig. 5. Effects of ATP $(0.1 \mathrm{~mm})$ on the isolated membrane currents in modified Ringer solutions. A) Voltage-current relationships in Na-free Ringer, B) in Cafree, EDTA, TTX Ringer, and C) in Mn Ringer solutions before $(O, \square)$ and 5-10 min after application $(\boldsymbol{\theta})$ of ATP. The circles denote peak value of the inwardly directed current and the squares, terminal current levels at the end of pulses of different amplitude. 
Ringer solution (solution B) ATP produced a marked augmentation of the Ca inward current $\left(I_{\mathrm{Ca}}\right)$ despite a considerable increase of the outward current (Fig. $5 \mathrm{~A})$. The threshold as well as the peak of the $I_{\mathrm{Ca}}$ were shifted to more negative potentials. The tension development depending on the $I_{\mathrm{Ca}}$ was also markedly augmented (figure is not shown). In the Ca-free EDTA solution (solution C) with freshly added TTX $\left(5 \times 10^{-7} \mathrm{~g} / \mathrm{ml}\right)$, the slow Na inward current $\left(I_{\mathrm{Nas}}\right)$ appeared extremely prolonged and often a spontaneous activity occurred. When ATP was introduced, the $I_{\mathrm{Nas}}$ shortened and the spontaneous activity ceased, suggesting an inhibitory action of ATP on $I_{\mathrm{Nas}}$. In the voltage-current relationship (Fig. 5B), however, the $I_{\mathrm{Nas}}$ appeared rather enhanced at the higher voltages. The reason for this is not clear at present.

In the Mn Ringer solution (solution D), in which the slow inward currents $\left(I_{\mathrm{Ca}}, I_{\mathrm{Nas}}\right)$ were eliminated, neither the remaining leaky current $\left(I_{1}\right)$ nor the anomalous rectification $\left(I_{\mathrm{K}_{1}}\right)$ was altered by ATP, while the delayed outward current $\left(I_{\mathrm{x}}\right)$ was slightly diminished (Fig. 5C). It must be noted, however, that no increase in the leaky current and outward current was produced in the Ca-free, EDTA or Mn Ringer solutions. The increase of these currents (see Fig. 5A) may be considered due to an excess of $\mathrm{Ca}$ entering the cell and consequent increase of $\mathrm{K}$ permeability (ISENBERG, 1975).

\section{Effects of ATP on the tension components}

Recently, in frog myocardium two components of contractile tension have been identified; a phasic component dependent on the calcium inward current
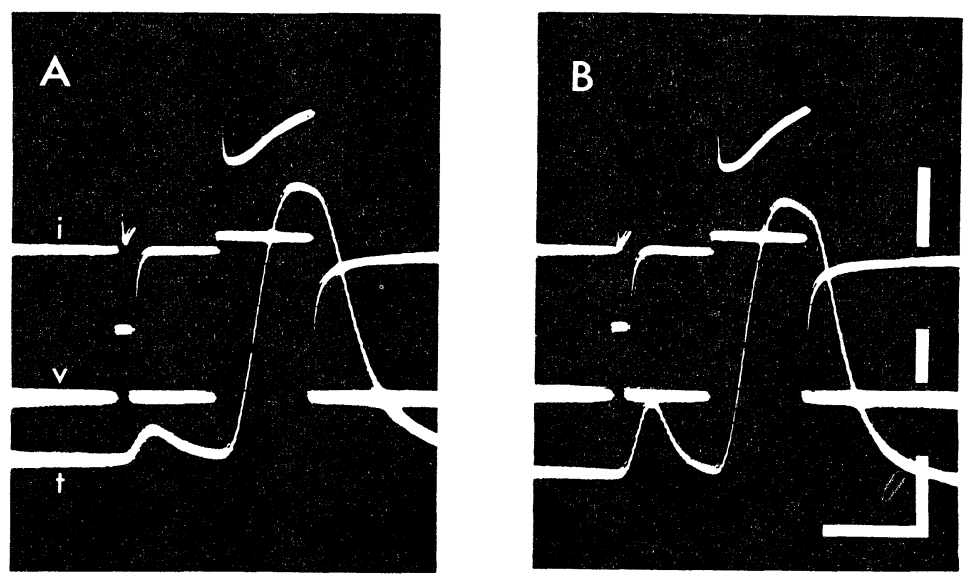

Fig. 6. Effects of ATP $(0.1 \mathrm{~mm})$ on $I_{\mathrm{Ca}}$-dependent and independent tensions in response to small $(70 \mathrm{mV}, 0.15 \mathrm{sec})$ and large depolarizing pulses $(150 \mathrm{mV}, 1.0 \mathrm{sec})$, respectively. A) Control. B) A record $5 \mathrm{~min}$ after ATP. $I_{\mathrm{Ca}}$-dependent tension increases, while $I_{\mathrm{Ca}}$ independent terminal tension was inhibited. TTX $\left(5 \times 10^{-7} \mathrm{~g} / \mathrm{ml}\right)$ was present, and holding potential was $-70 \mathrm{mV}$ throughout. Vertical calibrations from the top to bottom are $20 \mu \mathrm{A}, 50 \mathrm{mV}$ and $0.02 \mathrm{~g}$. Horizontal calibration is $1.0 \mathrm{sec}$. 
$\left(I_{\mathrm{Ca}}\right)$ and a tonic component independent on $I_{\mathrm{Ca}}$ (VASSORT and ROUGIER, 1972; LÉOTY and REYMOND, 1972; EINWÄCHTER et al., 1972; Goto et al., 1974). In Fig. 6A, the phasic tension component was elicited by a short weak depolarizing pulse $(0.15 \mathrm{sec}, 70 \mathrm{mV})$ and the tonic component, by a long strong depolarizing pulse $(1.0 \mathrm{sec}, 150 \mathrm{mV})$. When ATP $(0.1 \mathrm{~mm})$ was introduced, the phasic tension component was markedly augmented, while the tonic component was rather depressed (Fig. 6B).

A

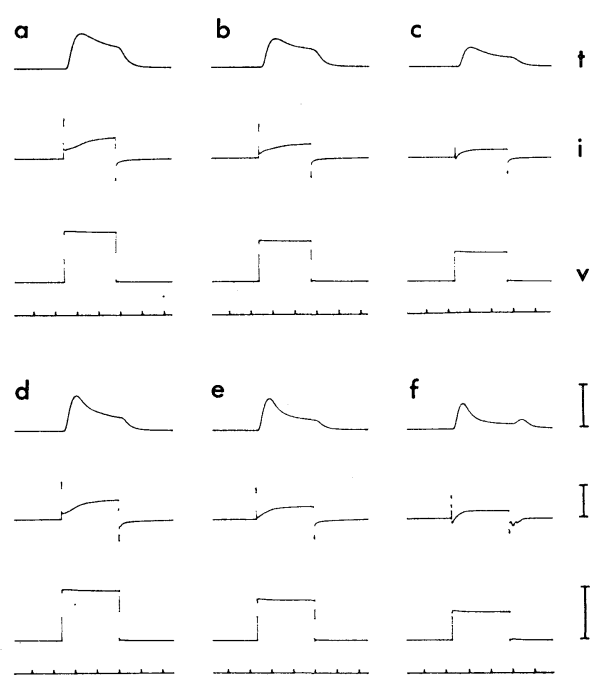

B

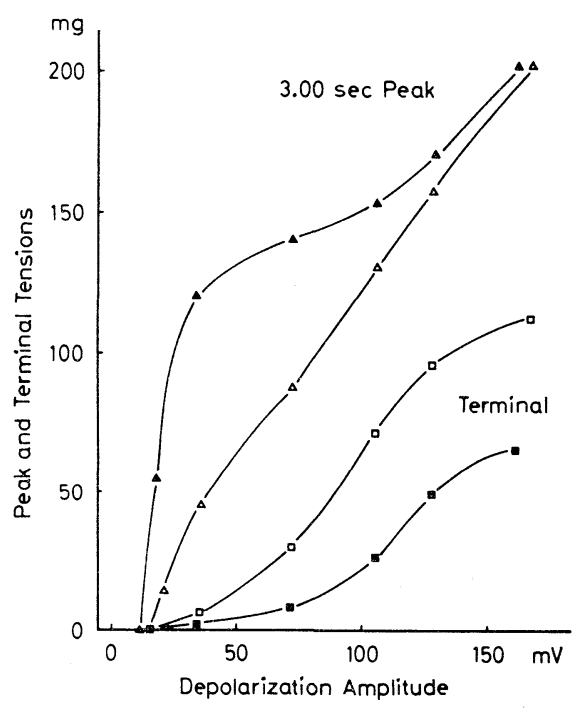

Fig. 7. A) Effects of ATP $(0.2 \mathrm{~mm})$ on the phasic and tonic tensions $(t)$ and the membrane current (i) in response to long-lasting ( $2.7 \mathrm{sec})$ depolarizing pulses (v). a, b, c) Control records. d, e, f) The records 3-5 min after the application of ATP. An undesirable off-response occurred in f. Vertical calibrations are $0.05 \mathrm{~g}, 10 \mu \mathrm{A}$ and $100 \mathrm{mV}$. Time calibration marks $1 \mathrm{sec}$. B) Membrane voltage-tension relationships determined with long depolarizing pulses of $3.0 \mathrm{sec}$. The peak $(\triangle, \mathbf{\Delta})$ and terminal tensions $(\square, \mathbf{a})$ before and 7-10 min after ATP $(0.2 \mathrm{mM})$ were plotted. Open symbols are controls and closed ones, after ATP. A marked augmentation of peak tension at low voltages and an inhibition of terminal tension at higher voltages are seen.

Figure 7A illustrates the tension development and membrane current in response to long-lasting $(2.7 \mathrm{sec})$ depolarization of different intensities. The upper panels of the figure show control records and the lower panels, the records taken 5-10 min after application of ATP $(0.2 \mathrm{mM})$. ATP produced an augmentation of initial phasic tension as well as the slow inward current, while the tonic tension toward the end of pulse was markedly inhibited (c, f). When the depolarizing pulse was stronger than $90 \mathrm{mV}(\mathrm{a}, \mathrm{d})$, no more augmentation of the initial tension occurred but inhibition of the terminal tonic tension was still produced. Figure 7B illustrates the effects of ATP $(0.2 \mathrm{mM})$ on the voltage-tension relationships 
determined with long depolarizing pulses of 3 sec. As for the peak tension, ATP again augmented the tension development at the low voltage range where $I_{\mathrm{Ca}}$ flowed, while it produced a considerable inhibition of the tonic terminal tension at higher voltages.

\section{Effects of adenosine, $A M P$, and ADP as compared with those of ATP}

Generally, adenosine as well as AMP appeared far less potent than ATP, and needed 10-20 times more doses to produce detectable effects, while ADP needed intermediate doses. Figure 8 shows the effect of adenosine $(1.0 \mathrm{~mm})$ on the $I_{\mathrm{Ca}}$-dependent and independent tensions which was examined by small and large depolarizing pulses in succession as before. Adenosine merely produced a depression of $I_{\mathrm{Ca}}$-independent tonic tension, and no positive inotropic effect was observed so far under voltage clamp conditions. In unclamped conditions, however, a slight and temporal augmentation of tension was often produced, accompanied by a prolongation of the action potential.

AMP (0.5-2.0 mM) produced effects similar to those with adenosine. Figure
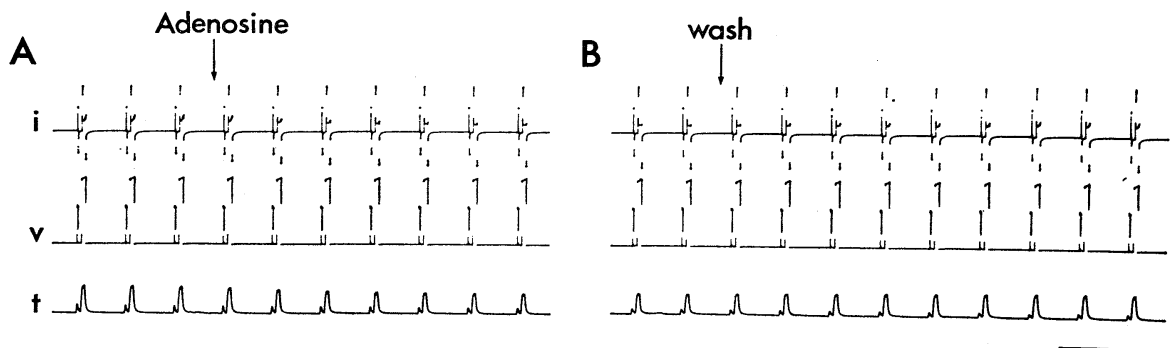

C

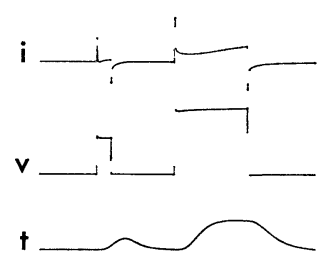

D

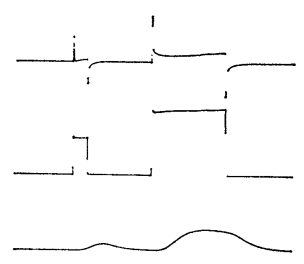

$\mathbf{E}$

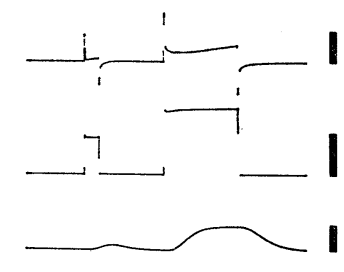

Fig. 8. Effects of adenosine $(1.0 \mathrm{~mm})$ on the membrane current (i) and the tension ( $\mathrm{t}$ ) under voltage clamp (v). Small $(80 \mathrm{mV}, 0.2 \mathrm{sec})$ and large $(150 \mathrm{mV}, 1 \mathrm{sec})$ double pulses were applied repeatedly in order to see the effects on the $I_{\mathrm{Ca}}$-dependent and independent tension responses. A, B) Continuous slow record with 2 min interruption. C, D, E) The faster records before, $3 \mathrm{~min}$ after application, and $5 \mathrm{~min}$ after washing, respectively. Because of the repetitive strong depolarizations, the tension responses were gradually depressed with time, however, no sign of augmentation of $I_{\mathrm{Ca}}$-dependent tension could be seen after adenosine, while an inhibition of $I_{\mathrm{Ca}}$-independent tonic tension occurred. Vertical calibrations are $20 \mu \mathrm{A}, 100 \mathrm{mV}$ and $0.1 \mathrm{~g}$. Time calibrations mark $10 \mathrm{sec}$ and $1 \mathrm{sec}$ for the slow $(\mathrm{A}, \mathrm{B})$ and fast records $(\mathrm{C}, \mathrm{D}, \mathrm{E})$, respectively. 
4B illustrates the effects of AMP (1.0 mM) on the voltage-current relationships in TTX $\left(10^{-6} \mathrm{~g} / \mathrm{ml}\right)$ Ringer solution. AMP did not alter the slow inward current at all. The delayed outward current was initially depressed but later augmented. The leaky membrane current and anomalous rectification were not changed. Quite comparable results were also obtained with adenosine in the same concentration (Fig. 8). Thus, it became clear that adenosine and AMP did not alter the $I_{\mathrm{Ca}}$ and $I_{\mathrm{Ca}}$-dependent tension but depressed the $I_{\mathrm{Ca}}$-independent tension. The initial depression of the outward current may explain the temporal prolongation of action potential and enhancement of contraction in unclamped conditions.

Meanwhile, ADP $(0.5 \mathrm{~mm})$ produced an apparent augmentation of $I_{\mathrm{Ca}}$ and $I_{\mathrm{Ca}}$-dependent tension under voltage clamp. At a later phase the delayed outward current was increased while the tonic tension was depressed. Thus, ADP showed effects quite similar to those with ATP, but it appeared considerably (3-5 times) less potent. These observations indicate that energy-rich phosphate bond or bonds $(\sim \mathrm{P})$ were indispensable for the augmentation of $I_{\mathrm{Ca}}$ and $I_{\mathrm{Ca}^{-}}$ dependent tension.

\section{DISCUSSION}

The results of present experiments indicate that ATP and other adenosine compounds acting on the plasma membrane produce alteration of the membrane currents and modification of the excitation-contraction coupling. ATP and ADP in low concentrations produced an augmentation of the $I_{\mathrm{Ca}}$ and $I_{\mathrm{Ca}}$-dependent phasic tension and a late enhancement of the delayed outward current. Meanwhile, AMP and adenosine did not alter the $I_{\mathrm{Ca}}$ and $I_{\mathrm{Ca}}$-dependent tension and initially depressed the delayed outward current. All adenosine compounds, however, inhibited the $I_{\mathrm{Ca}}$-independent tonic tension. These observations under voltage clamp can account for the changes in configuration of the action potential, and the nature of the initial positive and late negative inotropic effects of the adenosine compounds in unclamped conditions.

What is puzzling, however, is that almost all studies with isolated mammalian myocardium have shown only varying degree of negative inotropic effects of exogenously applied ATP and adenosine compounds (HollaNDER and WeBB, 1957; MeINERTz et al., 1973) except the membrane permeable cyclic AMP (SKeleton et al., 1970; Bertelli et al., 1972; MeINERTZ et al., 1973). According to extensive studies by HollaNDER and WeBB (1957), the depression of contraction of the rat atrium was accompanied by a marked shortening of action potential due to an increased rate of repolarization. They estimated that the purine-riboside moiety is the basic unit required for activity and combination of this group with sites in the membrane leads to an enhancement of the increase in potassium permeability following depolarization. These results appeared to be very compatible with those 
of late effects of the adenosine compounds on the frog atrium, in which a depression of contractility was accompanied more or less by an increase of the delayed outward current. Schrader et al. (1975), however, have revealed that adenosine at micromolar concentrations depressed the slow action potential of potassium-depolarized guinea-pig atrium, and suggested a possible inhibitory action on $\mathrm{Ca}$ influx. Although in our case with the bullfrog atrium, no appreciable inhibition of $I_{\mathrm{Ca}}$ was observed, and the tonic tension was markedly suppressed. Therefore, some inhibitory action of adenosine on $\mathrm{Ca}$ influx could not be denied especially when species difference was considered.

Another puzzling problem is the absence of the initial inotropic effect of $\sim \mathrm{P}$ in the mammalian hearts. In a report by MeINERTz et al. (1973), however, Fig. 6 clearly indicated a recovery of contractile tension by ATP and ADP in spite of their dominant depressive action, while no sign of recovery occurred in cases of AMP and adenosine. Meanwhile, we have clarified that adenosine compounds elicit two aspects of actions, initial positive and late negative inotropic effects, and these actions become less dominant in the order of ATP, ADP, AMP and adenosine. Therefore, we are inclined to consider that only difference in response between the frog and mammalian myocardium is in the grade of appearance of the counteracting effects. The reason why the depressive action is dominant in the mammalian heart still remains unsolved, however 1) temperature difference between the cold- and warm-blooded animals, 2) absence of $\mathrm{Mg}$ ions in the bathing solution for the former, and 3) other intrinsic difference in membrane characteristics might be problems awaiting solution. $I_{\mathrm{Ca}}$ is known to increase at low temperature (Goто et al., 1976a), and the adenosine compounds, especially ATP chelating with $\mathrm{Mg}$, act on the membrane in the mammalian heart (DANIEL and IRWIN, 1965).

The mechanism of action of $\sim \mathrm{P}$ to produce an enhancement of the $I_{\mathrm{Ca}}$ and delayed outward current are unknown at present. Apparent facts are that these effects are quite similar to those of adrenaline which is found to increase the $I_{\mathrm{Ca}}$ and delayed outward current $I_{\mathrm{x}}$, and generally believed to act via cyclic AMP (Tsien et al., 1972; Tsien, 1973; Reuter, 1974). However, the effects of $\sim P$ could not be eliminated by $\beta$-adrenergic blockers. Besides, it was found recently that GTP (guanosine triphosphate) as well as AMP-PNP (adenylyl-imidodiphosphate), an unhydrolysable ATP analogue, also produced the same effects as ATP (Goto et al., 1976b). Therefore, it becomes highly probable that the nucleotides with $\sim \mathrm{P}$ directly act on the membrane to produce an adrenaline-like effects without being metabolized.

\section{REFERENCES}

Antoni, H., Engstfeld, G., und Fleckenstein, A. (1960) Inotrope Effekte von ATP und Adrenalin am hypodynamen Froschmyokard nach elektromechanischer Entkuppelung durch $\mathrm{Ca}^{++}$-Entzug. Pflügers Arch. Ges. Physiol., 272: 91-106.

Bertelli, A., BiAnchi, C., and BeAni, L. (1972) Effects of AMP and cyclic AMP on the mechan- 
ical and electrical activity of isolated mammalian atria. Eur. J. Pharmacol., 19: 130-133.

Brown, H. F. and NoBle, S. J. (1969) Membrane currents underlying delayed rectification and pacemaker activity in frog atrial muscle. J. Physiol., 204: 717-736.

Cheneval, J. P., Hyde, A., Blondel, B., and Girardier, L. (1972) Heart cells in culture. Metabolism, action potential and transmembrane ionic movements. J. Physiol. (Paris), 64: $413-430$.

Coraboeuf, E. (1974) Membrane electrical activity and double component contraction in cardiac tissue. J. Mol. Cell. Cardiol., 6: 215-225.

DANIEL, D. D. and IRwIN, J. (1965) On the mechanism whereby certain nucleotides produce contractions of smooth muscle. Can. J. Physiol. Pharmacol., 43: 89-109.

EINWÄCHTER, H. M., HAAS, H. G., and KeRN, R. (1972) Membrane current and contraction in frog atrial fibres. J. Physiol., 227: 141-171.

GIRARDIER, L. (1971/72) Dynamic energy partition in cultured heart cells. Cardiology, 56: $88-92$.

Goto, M., WAdA, Y., and SAIto, M. (1974) Tension components and tension fall of the bullfrog atrial muscle during depolarization. Jap. J. Physiol., 24: 359-375.

Goto, M., Saito, M., Ikemoto, Y., and Tsuda, Y. (1976a) Effects of temperature on membrane currents of the frog myocardium. Proc. Jap. Acad., 52: 389-392.

Goto, M., YATANI, A., and TsudA, Y. (1976b) Membrane calcium current in cardiac excitation -Effects of ATP, GTP and Na-pump studied on the bullfrog myocardium. 8th Internat. Meeting of ISGR in Cardiac Metabolism, S9-10.

Hollander, P. B. and WebB, J. L. (1957) Effects of adenine nucleotides on the contractility and membrane potentials of rat atrium. Circ. Res., 5: 349-353.

ISENBERG, G. (1975) Is potassium conductance of cardiac Purkinje fibres controlled by $\left[\mathrm{Ca}^{2+}\right]_{\mathrm{i}}$ ? Nature, 253: 273-274.

LÉOty, C. and ReYmond, G. (1972) Mechanical activity and ionic currents in frog trabeculae. Pflügers Arch. Ges. Physiol., 334: 114-128.

MACLEOD, D. P. and DANIEL, E. E. (1965) Influence of glucose on the transmembrane action potential of anoxic papillary muscle. J. Gen. Physiol., 48: 887-899.

MacLeod, D. P. and Prasad, K. (1969) Influence of glucose on the transmembrane action potential of papillary muscle. Effects of concentration, phlorizin and insulin, nonmetabolizable sugars, and stimulators of glycolysis. J. Gen. Physiol., 53: 792-815.

MCDonald, T. F., Hunter, E. G., and MacLeod, D. P. (1971) Adenosinetriphosphate partition in cardiac muscle with respect to transmembrane electrical activity. Pflügers Arch. Ges. Physiol., 322: 95-108.

MCDonald, T. F. and MACLeod, D. P. (1971) Anoxia-recovery cycle in ventricular muscle: Action potential duration, contractility and ATP content. Pflügers Arch. Ges. Physiol., 325: 305-322.

MCDonald, T. F. and MACLeod, D. P. (1973) Metabolism and the electrical activity of anoxic ventricular muscle. J. Physiol., 229: 559-582.

MeInertz, T., Nawrath, H., and Scholz, H. (1973) Influence of cyclization and acyl substitution on the inotropic effects of adenine nucleotides. Naunyn-Schmiedeberg's Arch. Pharmacol., 278: 165-178.

PrasAD, K. and MACLEOD, D. P. (1969) Influence of glucose on the transmembrane action potential of guinea-pig papillary muscle. Metabolic inhibitors, ouabain, and calcium chloride, and their interaction with glucose, sympathomimetic amines and aminophylline. Circ. Res., 24: 939-950.

REUTER, H. (1974) Localization of beta adrenergic receptors, and effects of noradrenaline and cyclic nucleotides on action potentials, ionic currents and tension in mammalian cardiac muscle. J. Physiol., 242: 429-451. 
Rosenblum, I. and SteIn, A. A. (1964) Mechanism of the positive inotropic action of purine nucleosides in isolated atria. J. Pharmacol. Exp. Ther., 145: 78-82.

SchneIDeR, J. A. and Sperelakis, N. (1975) Slow $\mathrm{Ca}^{2+}$ and $\mathrm{Na}^{+}$responses induced by isoproterenol and methylxanthines in isolated perfused guinea-pig hearts exposed to elevated $\mathrm{K}^{+}$. J. Mol. Cell. Cardiol., 7: 249-273.

SChrader, J., Rubio, R., and Berne, R. M. (1975) Inhibition of slow action potentials of guinea pig atrial muscle by adenosine: A possible effect on $\mathrm{Ca}^{2+}$ influx. J. Mol. Cell. Cardiol., 7: 427-433.

Skeleton, L., Levey, G. S., and Epstein, S. E. (1970) Positive inotropic effects of dibutyryl cyclic adenosine 3', 5'-monophosphate. Circ. Res., 26: 35-43.

Tsien, R. W. (1973) Adrenaline-like effects of intracellular iontophoresis of cyclic AMP in cardiac Purkinje fibres. Nature New Biol., 245: 120-122.

Tsien, R. W., Giles, W., and Greengard, P. (1972) Cyclic AMP mediates the effects of adrenaline on cardiac Purkinje fibers. Nature New Biol., 240: 181-183.

VASSORT, G. and RoUGIER, O. (1972) Membrane potential and slow inward current dependence of frog cardiac mechanical activity. Pflügers Arch. Ges. Physiol., 331: 191-203. 